\title{
A transverse isotropic model for microporous solids - Application to coal matrix adsorption and swelling
}

D.N. Espinoza, ${ }^{1}$ M. Vandamme, ${ }^{1}$ P. Dangla, ${ }^{1}$ J.-M. Pereira ${ }^{1}$, and S.

Vidal-Gilbert $^{2}$

Corresponding author: D. N. Espinoza, Université Paris-Est, Laboratoire Navier (UMR 8205), ENPC, CNRS, IFSTTAR, 6-8 Av. Blaise Pascal, 77420, Champs-sur-Marne, FRANCE (nicolas.espinoza@enpc.fr)

${ }^{1}$ Université Paris-Est, Laboratoire Navier

(UMR 8205), ENPC, CNRS, IFSTTAR,

France

${ }^{2}$ Total S.A., Unconventional Gas

Resources, France 
X - 2 ESPINOZA ET AL.: A TRANSVERSE ISOTROPIC MODEL FOR MICROPOROUS SOLIDS

3 Abstract. Understanding the adsorption-induced swelling in coal is crit-

4 ical for predictable and enhanced coal bed methane production. The coal ma-

5 trix is a natural anisotropic disordered microporous solid. We develop an elas-

6 tic transverse isotropic poromechanical model for microporous solids which

couples adsorption and strain through adsorption stress functions, and ex-

presses the adsorption isotherm as a multivariate function depending on fluid

9 pressure and solid strains. Experimental data from the literature help invert-

${ }_{10}$ ing the anisotropic adsorptive-mechanical properties of Brzeszcze coal sam-

${ }_{11}$ ples exposed to $\mathrm{CO}_{2}$. Main findings include: (1) adsorption-induced swelling

${ }_{12}$ can be modeled by including fluid-specific and pressure-dependent adsorp-

tion stress functions into equilibrium equations, (2) modeling results suggest

that swelling anisotropy is mostly caused by anisotropy of the solid mechan-

ical properties, and (3) the total amount of adsorbed gas measured by immersing coal in the adsorbate overestimates adsorption amount compared to in-situ conditions up to $\sim 20 \%$. The developed fully coupled model can be upscaled to determine the coal seam permeability through permeabilitystress relationships. 


\section{Introduction}

The understanding of adsorption of gases in mesoporous and microporous solids is important for applications in gas capture, gas separation, and gas desorption/adsorption in sedimentary rocks. Micropores are defined by the IUPAC as pores with width not exceeding $2 \mathrm{~nm}$. We consider here a broader definition of microporous solids including porous solids with pores sized in the order of a few nanometers. Natural microporous solids include coal, kerogen, zeolites, and gas hydrates; while artificial microporous solids include microcarbon and metal organic frameworks among others [Ravikovitch and Neimark, 2006; Mazumder et al., 2006; Vandenbroucke and Largeau, 2007; Sloan and Koh, 2008; Kowalczyk et al., 2008; Neimark et al., 2011]. From another point of view, microporous solids can be classified as regards their structure in crystalline (ordered structure: metal organic frameworks, zeolites, hydrates) or disordered (coal, kerogen, microporous carbon). Nanosized micropores can host just a few fluid molecules. The adsorption of fluids in these pores can lead to their expansion or contraction depending on the pore size, geometry, and fluid-solid interaction [Kowalczyk et al., 2008; Pijaudier-Cabot et al., 2011; Brochard et al., 2012]. Macroscopically, adsorption-driven changes of pore size or pressure upscale as strains (or stresses if strains are prescribed).

This coupling between strain and adsorption is particularly important in the context of underground adsorptive geomaterials, such as coal and organic shales [Busch et al., 2008; Weniger et al., 2010]. Hydrocarbon production from these reservoirs imposes significant changes in stresses coupled with adsorption or desorption leading to strains which affect the aperture and permeability of natural and generated fractures. The adsorption-strain 
$\mathrm{X}-4$

ESPINOZA ET AL.: A TRANSVERSE ISOTROPIC MODEL FOR MICROPOROUS SOLIDS

41

42

43

44

45

46

coupling is critical to defining production rates of natural gas from highly-adsorptive coal bed seams [Palmer and Mansoori, 1998; Pan and Connell, 2012].

The adsorption and swelling of various gases including carbon dioxide $\mathrm{CO}_{2}$, methane $\mathrm{CH}_{4}$, and nitrogen $\mathrm{N}_{2}$ in coal has been largely studied in the past decades [Reucroft and Sethuraman, 1987; Ceglarska-Stefanska and Czaplinski, 1993; Levine, 1996; CeglarskaStefanska and Zarebska, 2002; Mazumder et al., 2006; Pini et al., 2009]. Adsorbed amounts are usually measured in the laboratory in terms of excess adsorbed amount, that is, the amount of fluid in excess of the amount of fluid which would occupy the pore volume in bulk conditions. In general for low-medium gas pressure, up to 10 MPa, the rule "the greater the pressure, the greater the total adsorbed amount" is valid. In this range, coal swelling is usually proportional to the amount of adsorbed gas. For higher pressures, the bulk fluid pressure compresses the solid skeleton and may prevail over adsorptioninduced swelling [Moffat and Weale, 1954; Pan and Connell, 2007; Hol and Spiers, 2012]. In fact, recent studies show that the application of compressive confining stresses (and ensuing strains) to coal swollen and equilibrated with $\mathrm{CO}_{2}$ at a certain pressure induce the expulsion of adsorbed gas [Hol et al., 2011, 2012]. This desorption induced by mechanical stresses is not due to the loss of pore accessibility caused by permeability reduction upon the application of compressive external stresses, phenomenon which is also observed in coal [Pone et al., 2009; Wang et al., 2011].

Such a particular behavior of coal motivated the extension of the theory of poromechanics to include adsorption phenomena in microporous solids. Brochard et al. [2012] proposed a set of poromechanical equations valid for linear elastic isotropic microporous solids which considers as main variable the total amount of adsorbed fluid as a function 
ESPINOZA ET AL.: A TRANSVERSE ISOTROPIC MODEL FOR MICROPOROUS SOLIDS $\quad \mathrm{X}-5$ 
X - 6 ESPINOZA ET AL.: A TRANSVERSE ISOTROPIC MODEL FOR MICROPOROUS SOLIDS

adsorbing microporous solids which exhibit transverse isotropic properties. The interested reader will find similar theoretical developments applied to various poromechanical problems in [Coussy, 2004, 2010]. The theory of poroelasticity for anisotropic macroporous solids has been revisited by several authors [Cheng, 1997; Coussy, 2004; Cowin, 2004].

\subsection{Energy conservation}

Consider a representative elementary volume of a microporous solid with free energy per unit volume $f[\mathrm{~J} / \mathrm{L}]$, subjected to stresses $\sigma_{i j}[\mathrm{~Pa}]$, and whose adsorbed fluid has a molar chemical potential $\mu[\mathrm{J} / \mathrm{mol}]$. Energy conservation under isothermal conditions dictates

$$
d f=\sum_{i, j} \sigma_{i j} d \varepsilon_{i j}+\mu d n
$$

being $\varepsilon_{i j}$ the strain tensor [-], and $n$ the number of moles of fluid per unit volume of undeformed microporous solid [mol/L]. Strains are calculated respect to the original configuration (Lagrangian formulation). By changing variables, the following holds

$$
d(f-n \mu)=\sum_{i, j} \sigma_{i j} d \varepsilon_{i j}-n d \mu
$$

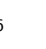
S (1) exprats (1) this purpose. 


\subsection{Derivation of equations of state}

Let us apply Maxwell's relation on the previous energy conservation equality (Eq. 2),

$$
\frac{\partial^{2}(f-n \mu)}{\partial \varepsilon_{i j} \partial \mu}=\frac{\partial^{2}(f-n \mu)}{\partial \mu \partial \varepsilon_{i j}}
$$

Derivation leads to

$$
\left.\frac{\partial \sigma_{i j}}{\partial \mu}\right|_{\varepsilon_{k l \neq i j}}=-\left.\frac{\partial n}{\partial \varepsilon_{i j}}\right|_{\mu, \varepsilon_{k l \neq i j}}
$$

The equality holds for strains $\varepsilon_{k l \neq i j}$ constant. By integrating this equation on the molar chemical potential $\mu$ we obtain the following equation

$$
\sigma_{i j}=\Psi_{i j}(\underline{\underline{\varepsilon}})-\left.\int_{-\infty}^{\mu} \frac{\partial n}{\partial \varepsilon_{i j}}\right|_{\mu, \varepsilon_{k l \neq i j}} d \mu
$$

where $\Psi_{i j}$ results from this integration and, thus, is a function independent from the fluid chemical potential $\mu$. The molar chemical potential $\mu$ can be re-written using GibbsDuhem relation for isothermal conditions $d \mu=\bar{V}_{b}(p) d p$, where $\bar{V}_{b}$ is the molar volume of the fluid in bulk conditions $[\mathrm{L} / \mathrm{mol}]$ as a function of temperature and pressure, and $p$ is the thermodynamic pressure of the fluid $[\mathrm{Pa}]$ defined as the pressure of the bulk fluid at the same chemical potential as the adsorbed phase. Hence, Eq. (5) can be written as follows

$$
\sigma_{i j}=\Psi_{i j}(\underline{\underline{\varepsilon}})-\left.\int_{0}^{p} \frac{\partial n}{\partial \varepsilon_{i j}}\right|_{p, \varepsilon_{k l \neq i j}} \bar{V}_{b}(p) d p
$$

The first term to the right of the equality $\Psi_{i j}$ represents the "dry" response of the specimen to strains (without the fluid phase) and the integral term represents the response D R A F T September 11, 2013, 6:53pm

D R A F T 
X - 8 ESPINOZA ET AL.: A TRANSVERSE ISOTROPIC MODEL FOR MICROPOROUS SOLIDS

to fluid loading as a function of fluid pressure and solid strain. For example, assuming linear elasticity, isotropic material properties, and that the fluid is in bulk conditions, Brochard et al. [2012] show that Eq. (6) permits recovering the classical equations of poroelasticity $\sigma=K \epsilon-b p$, where $K$ is the drained bulk modulus, $\epsilon$ is the volumetric strain, and $b$ is the Biot coefficient).

\subsection{Simplification for transverse isotropic coal}

Linear elastic transverse isotropy. The functions $\Psi_{i j}$ depend on strains $\underline{\underline{\varepsilon}}$ only, hence, any linear or non-linear elastic constitutive law may be used. We use transverse isotropic linear elasticity for functions $\Psi_{i j}$ in this formulation. Transverse isotropic materials are defined by an axis of symmetry in their elastic properties (say axis 3 in this development). The reduced stiffness matrix in Voigt notation $C_{i j}$ has 5 independent constants. Thus, the "dry" response of a generic transversely isotropic porous solid $\sigma_{i j}=\Psi_{i j}(\underline{\underline{\varepsilon}})$ is

$$
\left\{\begin{array}{l}
\sigma_{11}=C_{11} \varepsilon_{11}+C_{12} \varepsilon_{22}+C_{13} \varepsilon_{33} \\
\sigma_{22}=C_{12} \varepsilon_{11}+C_{11} \varepsilon_{22}+C_{13} \varepsilon_{33} \\
\sigma_{33}=C_{13} \varepsilon_{11}+C_{13} \varepsilon_{22}+C_{33} \varepsilon_{33} \\
\sigma_{23}=2 C_{44} \varepsilon_{23} \\
\sigma_{31}=2 C_{44} \varepsilon_{31} \\
\sigma_{12}=\left(C_{11}-C_{12}\right) \varepsilon_{12}
\end{array}\right.
$$

Deformation can be expressed in terms of engineering elastic constants $E$ (Young modulus in direction 1 and 2), $E_{3}$ (Young modulus in direction 3), $\nu$ (Poisson ratio in plane $1-2$ ), $\nu_{3}$ (Poisson ratio in planes 1-3 and 2-3), and $G_{3}$ (shear modulus in plane 1-3 and $2-3)$ as $\varepsilon_{k l}=\Psi_{k l}^{\prime}(\underline{\underline{\sigma}})$ 


$$
\left\{\begin{array}{l}
\varepsilon_{11}=(1 / E) \sigma_{11}-(\nu / E) \sigma_{22}-\left(\nu_{3} / E_{3}\right) \sigma_{33} \\
\varepsilon_{22}=-(\nu / E) \sigma_{11}+(1 / E) \sigma_{22}-\left(\nu_{3} / E_{3}\right) \sigma_{33} \\
\varepsilon_{33}=-\left(\nu_{3} / E_{3}\right) \sigma_{11}-\left(\nu_{3} / E_{3}\right) \sigma_{22}+\left(1 / E_{3}\right) \sigma_{33} \\
2 \varepsilon_{23}=\left(1 / G_{3}\right) \sigma_{23} \\
2 \varepsilon_{31}=\left(1 / G_{3}\right) \sigma_{31} \\
2 \varepsilon_{12}=[2(1+\nu) / E] \sigma_{12}
\end{array}\right.
$$

Multivariate adsorption isotherm. The derivative $\partial n /\left.\partial \varepsilon_{i j}\right|_{p, \varepsilon_{k l \neq i j}}$ in the right hand side of Eq. (6) can be further developed if the total amount of adsorbed fluid $n\left(p, \varepsilon_{i j}\right)$ is known as a function of the thermodynamic pressure of the fluid $p$ and the strains of the microporous solid $\varepsilon_{i j}$. Considering small strains, this multivariate adsorption isotherm can be expressed as a first-order expansion with respect to strains, such that,

$$
n\left(p, \varepsilon_{i j}\right)=n_{0}(p)\left[1+c_{1}(p) \varepsilon_{11}+c_{2}(p) \varepsilon_{22}+c_{3}(p) \varepsilon_{33}\right]
$$

where $n_{0}(p)=n(p, \underline{\underline{0}})$ is the total amount of adsorbed fluid at zero solid strain, and $c_{1}(p)$, $c_{2}(p), c_{3}(p)$ are the adsorption-strain coupling functions for each direction [-]. Coefficients $c_{i}(p)$ capture the coupling between adsorption and strain, and depend on fluid pressure, type of gas, pore shape and size distribution. Brochard et al. [2012] performed molecular simulations of $\mathrm{CH}_{4}$ adsorption in disordered organic microporous solids and validated this first-order expansion (Eq. 9) in the isotropic case, for volumetric strains up to $\sim 10 \%$. Such strains are sufficiently large to consider that this first-order expansion is valid for coal in practical conditions. We will consider that this validity remains in the case of transverse isotropy. Also, Brochard et al. [2012] show that adsorption-strain coupling coefficients can be negative when adsorption induces pore shrinkage or positive if pore expansion prevails. Transverse isotropy in the adsorption-strain coupling imposes $c_{1}(p)=c_{2}(p)$. 
X - 10 ESPINOZA ET AL.: A TRANSVERSE ISOTROPIC MODEL FOR MICROPOROUS SOLIDS

Various adsorbing materials, including coal exposed at moderate gas pressure, are well described by Langmuir adsorption isotherms as a function of pressure or more appropriately as a function of the fluid fugacity [Fowler, 1935; Vandamme et. al., 2010; Hol et al., 2011]. Hence, assuming a Langmuir-type of adsorption as a function of pressure for the undeformed microporous coal leads to

$$
n_{0}(p)=n_{0}^{\max } \frac{p}{\beta+p}
$$

with $n_{0}^{\max }$ being the maximum total amount of adsorbed fluid at zero solid strain [mol/L], and $\beta$ the Langmuir pressure $[\mathrm{Pa}]$ at which one half of the adsorption capacity is reached while keeping zero solid strain.

From Eq. (9) and (10), the derivatives of $n\left(p, \varepsilon_{i j}\right)$ with respect to strains $\varepsilon_{i j}$ result:

$$
\left.\frac{\partial n}{\partial \varepsilon_{i j}}\right|_{p, \varepsilon_{k l \neq i j}}=c_{i}(p) n_{0}(p) \delta_{i j}
$$

Eq. (9) implicitly assumes that the principal directions of the tensor $\partial n /\left.\partial \varepsilon_{i j}\right|_{p, \varepsilon_{k l \neq i j}}$ coincide with the geometrical axes of symmetry. Hence, these derivatives are non-zero only with respect to strain components $\varepsilon_{i i}$ and vanish for shear strains components $\varepsilon_{i j}$ with $i \neq j$. Back to Eq. (6), adsorption-induced strains and stresses on the anisotropic microporous solid can be quantified with terms named $s_{i}^{a}(p)=\int_{0}^{p} \partial n /\left.\partial \varepsilon_{i j}\right|_{p, \varepsilon_{k l \neq i j}} \bar{V}_{b} d p$, which, with the help of Eq. (11), become

$$
s_{i}^{a}(p)=\int_{0}^{p} c_{i}(p) n_{0}(p) \bar{V}_{b}(p) d p
$$


ESPINOZA ET AL.: A TRANSVERSE ISOTROPIC MODEL FOR MICROPOROUS SOLIDS X - 11

We call these terms "adsorption stresses" as motivated by an analogy with the theory formulated by Ravikovitch and Neimark [2006]. Physically, these terms quantify the stresses needed to keep the microporous solid at zero volumetric strain during adsorption.

Final equations. Combining the linear elastic constitutive equations (Eq. 7) with adsorption stresses (Eq. 12), the set of equations (Eq. 6) becomes

$$
\left\{\begin{array}{l}
\sigma_{11}=C_{11} \varepsilon_{11}+C_{12} \varepsilon_{22}+C_{13} \varepsilon_{33}-s_{1}^{a}(p) \\
\sigma_{22}=C_{12} \varepsilon_{11}+C_{11} \varepsilon_{22}+C_{13} \varepsilon_{33}-s_{1}^{a}(p) \\
\sigma_{33}=C_{13} \varepsilon_{11}+C_{13} \varepsilon_{22}+C_{33} \varepsilon_{33}-s_{3}^{a}(p) \\
\sigma_{23}=2 C_{44} \varepsilon_{23} \\
\sigma_{31}=2 C_{44} \varepsilon_{31} \\
\sigma_{12}=\left(C_{11}-C_{12}\right) \varepsilon_{12}
\end{array}\right.
$$

The model relies on five mechanical parameters $C_{11}, C_{33}, C_{12}, C_{13}, C_{44}$ (stiffness coefficients which can be expressed as a function of $\left.E, \nu, E_{3}, \nu_{3}, G_{3}\right)$, one fluid equation of state $\bar{V}_{b}(p)$ at a given temperature, two characteristic total adsorption parameters $n_{0}^{\max }$ and $\beta$ for the microporous solid at zero strain, and two adsorption-strain coupling pressure-dependent functions $c_{1}(p)$ and $c_{3}(p)$.

\section{Application example - Unconstrained coal swelling}

Let us consider a piece of coal matrix immersed in $\mathrm{CO}_{2}$ under unconstrained displacement boundary conditions (unjacketed: no membrane or wall, the solid is free to swell), such that $\mathrm{CO}_{2}$ pressure applies isotropic loading and no shear on the solid $\left(\sigma_{11}=\sigma_{22}=\sigma_{33}=-p ; \sigma_{i j}=0\right.$ for $i \neq j$ ). The coal is in thermodynamical equilibrium, thus, the chemical potential of the bulk fluid at pressure $p$ is the same as the chemical potential of the adsorbed fluid. Isotropic loading in a transverse isotropic medium imposes $\varepsilon_{11}=\varepsilon_{22}$ in the general case $C_{11} \neq C_{12}$ (from Eq. 13), $\varepsilon_{11}=\varepsilon_{22}=\varepsilon_{1}$ the principal strain 
on the bedding plane, and $\varepsilon_{33}=\varepsilon_{3}$ the principal strain perpendicular to the bedding plane, hence, Eq. (13) reduces to

$$
\left\{\begin{aligned}
\sigma_{11}=\sigma_{22} & =-p=\left(C_{11}+C_{12}\right) \varepsilon_{1}+C_{13} \varepsilon_{3}-s_{1}^{a}(p) \\
\sigma_{33} & =-p=2 C_{13} \varepsilon_{1}+C_{33} \varepsilon_{3}-s_{3}^{a}(p)
\end{aligned}\right.
$$

Let us write the principal strains $\varepsilon_{1}$ and $\varepsilon_{3}$ as function of stresses using the engineering elastic constants. Swelling strains result

$$
\left[\begin{array}{l}
\varepsilon_{1} \\
\varepsilon_{3}
\end{array}\right]=\left[\begin{array}{cc}
\frac{1-\nu}{E} & -\frac{\nu_{3}}{E_{3}} \\
-2 \frac{\nu_{3}}{E_{3}} & \frac{1}{E_{3}}
\end{array}\right]\left[\begin{array}{l}
s_{1}^{a}(p)-p \\
s_{3}^{a}(p)-p
\end{array}\right]
$$

Recent experimental results show the swelling of cylindrical Brzeszcze coal specimens immersed in $\mathrm{CO}_{2}$ up to $100 \mathrm{MPa}$ of fluid pressure (specimen size $4 \mathrm{~mm}$ length and $4 \mathrm{~mm}$ diameter [Hol and Spiers, 2012]). Strains are measured in two perpendicular directions in the bedding plane (noted $\varepsilon_{x}$ and $\varepsilon_{y}$ ), at $45^{\circ}$ between the $x$ and $y$ axes, and perpendicular to the bedding plane (this latter noted $\varepsilon_{z}$ ). Results show a clear orthotropic swelling of coal specimens, being the strain perpendicular to the bedding plane the highest $\varepsilon_{z}>\varepsilon_{y} \sim \varepsilon_{x}$. We consider the major principal strain $\varepsilon_{3}=\varepsilon_{z}$. We calculate the other two principal strains from the original data set based on the three strains measured in the bedding plane. Figures 1-a and 1-d show the principal strains for two coal specimens 364-1 and 364-2, as named in the source reference. Although the experimental results show an orthotropic response, we fit a transverse isotropic model in views of upscaling to coal seams with transverse isotropic properties and to reduce the number of inverted parameters. The experimental principal strain $\varepsilon_{3}$ and the mean of the experimental principal strains on the bedding plane $\left(\varepsilon_{1}+\varepsilon_{2}\right) / 2$ are used to validate the transverse isotropic model. 
ESPINOZA ET AL.: A TRANSVERSE ISOTROPIC MODEL FOR MICROPOROUS SOLIDS X - 13

Additional data help us invert the coal adsorptive-mechanical properties; these data include: (1) total amount of adsorption in Brzeszcze coal immersed in $\mathrm{CO}_{2}$ up to $15 \mathrm{MPa}$ (estimated from excess adsorbed amount measurements at $45^{\circ} \mathrm{C}$ by Gensterblum et al. [2010] with best fitting adsorbed phase volume per unit mass of coal $V_{\text {ads }} / m_{\text {coal }}=0.055$ $\mathrm{cm}^{3} / \mathrm{g}$ - see Auxiliary Material); (2) the dry coal mass density $\rho \sim 1343 \mathrm{~kg} / \mathrm{m}^{3}$ [Hol et al., 2011]; (3) the molar volume of $\mathrm{CO}_{2}$ at $40^{\circ} \mathrm{C}$ as a function of pressure (from equation of state by Span and Wagner [1996]). The coal is expected to adsorb slightly less $\mathrm{CO}_{2}$ at $45^{\circ} \mathrm{C}$ than at $40^{\circ} \mathrm{C}$, temperature at which swelling strains are measured. In the calculation performed here to estimate total adsorbed amounts from excess adsorbed amounts, we adopt the procedure proposed by Ottiger et al. [2006]. We thus neglect the effect of mesopores and adsorption-induced deformations on the adsorption process, which is a very simplistic approach. However, correctly interpreting gravimetric adsorption data by taking into account the full coupling between adsorption and strain still remains a challenging issue. While this issue is not fully solved, in addition to the interpretation proposed here, as alternatives, one can aim at using models based directly on excess adsorption data (e.g., Vermorel et al. [2013a, b]) or instead at measuring total adsorbed amounts directly (e.g., as proposed by Hol et al. [2011]).

In order to bound the inverted parameters, we follow two paths for the inversion procedure. First, we explore the anisotropy of adsorption-induced strains, and conclude that assuming isotropic and pressure-independent adsorption stresses is reasonable for the analyzed coal and permits recovering a plausible estimate of the coal mechanical anisotropy. Second, mechanical isotropy is assumed and the adsorption-strain coupling coefficients are recovered (still considered pressure-independent), so that, the anisotropy 
X - 14 ESPINOZA ET AL.: A TRANSVERSE ISOTROPIC MODEL FOR MICROPOROUS SOLIDS

of adsorption-strain coupling coefficients is determined. Last, we show that introducing a pressure-dependent coupling coefficients $c_{1}(p) \neq c_{3}(p)$ (based on the experimentally measured swelling strains and anisotropic mechanical elastic constants) enables a better the fitting of the experimental data.

\subsection{Mechanical anisotropy and isotropic adsorption stresses}

We first investigate whether adsorption-induced stresses can be assumed isotropic or not. According to our poromechanical model (Eq. 15), having equal coupling coefficients $c_{1}(p)=c_{3}(p)$ or equivalently $s_{1}^{a}(p)=s_{3}^{a}(p)=s^{a}(p)$ leads to,

$$
\left\{\begin{array}{l}
\varepsilon_{1}=\left[s^{a}(p)-p\right]\left(\frac{1-\nu}{E}-\frac{\nu_{3}}{E_{3}}\right) \\
\varepsilon_{3}=\left[s^{a}(p)-p\right]\left(\frac{1-2 \nu_{3}}{E_{3}}\right)
\end{array}\right.
$$

which means that under such an assumption the ratio $\varepsilon_{1} / \varepsilon_{3}=f\left(E, E_{3}, \nu, \nu_{3}\right)$ should be constant and independent of gas pressure and adsorption stresses. Figures 1-b and 1e show the experimental ratios between the principal strains for both specimens. It is observed that $\varepsilon_{1} / \varepsilon_{3}$ and $\varepsilon_{2} / \varepsilon_{3}$ decrease slightly with pressure by about $\sim 10 \%$ for fluid pressure $p<10 \mathrm{MPa}$, which indicates slight anisotropy of adsorption stresses only in this range of pressure. Hence, as a first approximation we set adsorption stresses equal in all directions $s_{1}^{a}=s_{3}^{a}=s^{a}$ with constant adsorption coupling functions so that $c_{1}(p)=$ $c_{3}(p)=c$. Assuming isotropic adsorption stresses leads to recovering an upper bound for mechanical anisotropy, which can be assessed by the parameter $\left(C_{11}-C_{33}\right) /\left(2 C_{33}\right)$. Additional assumptions help reduce the number of inverted parameters: non-diagonal stiffness coefficients are approximately equal $C_{12} \sim C_{13}$ (as observed in many shales with weak anisotropy from an extensive data compilation by Wang [2002]), and one of the 
Poisson ratios is assumed $\nu_{3}=0.28$ according to typical coal Poisson ratios determined indirectly from elastic waves velocity [Morcote et al., 2010].

By assuming $C_{12} \sim C_{13}$, the following moduli ratio holds,

$$
\frac{E}{E_{3}}=\frac{\nu_{3}+\nu_{3} \nu-\nu}{\nu_{3}^{2}}
$$

hence, given $\nu_{3}, \nu=f\left(E / E_{3}\right)$. Given the total adsorbed amount and swelling principal strains of coal immersed in $\mathrm{CO}_{2}$ as a function of pressure $\left(\varepsilon_{1}, \varepsilon_{2}, \varepsilon_{3}\right)$, and a coupling coefficient $c$, the parameters $n_{0}^{\max }$ and $\beta$ can be determined to best fit Eq. (9). Therefore, the free fitting parameters are $E, E_{3}$, and $c$. The shear modulus in planes which contain the symmetry axis $G_{3}$ is not needed for this particular application.

We fit our model simultaneously to the swelling strain and total adsorption amount data by forward simulation and 2-norm error estimation. Modeled strains $\varepsilon_{1}$ and $\varepsilon_{3}$ are set to fit experimentally measured $\left(\varepsilon_{1}+\varepsilon_{2}\right) / 2$ and $\varepsilon_{3}$ respectively. The calculated error surfaces are available as Auxiliary Material. Figures 1-a,c,d,f show the best-fitting modeling results along with the experimental data and best fitting parameters. Notice that $E$ and $E_{3}$ are the specimen "dry" or "drained" moduli. The unjacketed response of the same specimens to Helium (specimen 364-1: $d \varepsilon_{3} / d p=0.0050 \% / \mathrm{MPa}, d \varepsilon_{1} / d p \sim 0.0040 \% / \mathrm{MPa}$; specimen $364-2: d \varepsilon_{3} / d p=0.0049 \% / \mathrm{MPa}, d \varepsilon_{1} / d p \sim 0.0040 \% / \mathrm{MPa}$ - original data set from Hol and Spiers [2012]) suggests stiffer moduli in the direction parallel to the bedding plane. From our inversion results, we indeed find that $E>E_{3}$. The inverted mechanical anisotropy in terms of the Thomsen parameter $\varepsilon^{*}=\left(C_{11}-C_{33} /\left(2 C_{33}\right)\right.$ is about 0.137 (specimen $\left.364-1\right)$ and 0.082 (specimen 364-2), in agreement with Thomsen parameters measured in other coals $\varepsilon^{*} \sim 0.05-0.10\left[\right.$ Morcote et al., 2010] and shales $\varepsilon^{*}=0.17 \pm 0.08$ [Wang, 2002]. 
X - 16 ESPINOZA ET AL.: A TRANSVERSE ISOTROPIC MODEL FOR MICROPOROUS SOLIDS

Inverted bulk moduli $K=4.21 \mathrm{GPa}$ for specimen $364-1$ and $K=3.58 \mathrm{GPa}$ for specimen 364 -

2 are in the range of values for bituminous coal: 0.79 to $5.3 \mathrm{GPa}$ (spanning several scales and loading rates [Mazumder, 2007; Morcote et al., 2010; Pan et al., 2010; Masoudian et al., 2013]).

\subsection{Mechanical isotropy and anisotropic adsorption stresses}

Let us now assume isotropic mechanical properties and find the pressure-independent adsorption-strain coupling coefficients $c_{1}$ and $c_{3}$ which best fit the experimental data. Having $E=E_{3}$ and $\nu=\nu_{3}$, Eq. (15) leads to

$$
\left\{\begin{array}{l}
\varepsilon_{1}=\frac{1-\nu}{E_{2}}\left[s_{1}^{a}(p)-p\right]-\frac{\nu}{E}\left[s_{3}^{a}(p)-p\right] \\
\varepsilon_{3}=-\frac{2 \nu}{E}\left[s_{1}^{a}(p)-p\right]+\frac{1}{E}\left[s_{3}^{a}(p)-p\right]
\end{array}\right.
$$

We simplify the problem similarly as done above by assuming one known Poisson ratio $\nu=0.28$. Foward simulation and error estimation let us recover the best fitting parameters $E, c_{1}$, and $c_{3}$. Figure 2 shows the simulation results for the best fitting parameters. Auxiliary Material contains the error surfaces for best fitting parameter determination. The fact that $c_{3}>c_{1}$ implies that adsorption stresses would be higher in the direction perpendicular to the bedding plane. We find that the upper bound for adsorption stress anisotropy is $\left(c_{3}-c_{1}\right) /\left(2 c_{1}\right) \sim 0.048$ for specimen $364-1$ and 0.030 for specimen $364-2$. The fitting is overall poorer than the one observed by concentrating anisotropy on mechanical elastic moduli.

\subsection{Pressure-dependent adsorption-strain coupling coefficients}

Let us use now the values of $E_{3}, E, \nu_{3}$, and $\nu$ found in Section 3.1 and relax the previous assumption of pressure-independent coupling coefficients. By taking the derivatives of Eq. 
(15) with respect to pressure and multiplying by the inverse of the compliance matrix, the following holds,

$$
\left[\begin{array}{c}
\frac{d s_{1}^{a}(p)}{d p}-1 \\
\frac{d s_{3}^{a}(p)}{d p}-1
\end{array}\right]=\left[\begin{array}{cc}
\frac{1-\nu}{E} & -\frac{\nu_{3}}{E_{3}} \\
-2 \frac{\nu_{3}}{E_{3}} & \frac{1}{E_{3}}
\end{array}\right]^{-1}\left[\begin{array}{c}
\frac{d \varepsilon_{1}}{d p} \\
\frac{d \varepsilon_{3}}{d p}
\end{array}\right]
$$

Hence, calculating the value of $d s_{i}^{a}(p) / d p$, the coupling coefficients follow from Eq. (12) and are equal to $c_{i}(p) \sim 8$ to 11 (Figure 3 -a,c - Note: $d \varepsilon_{1} / d p$ is calculated from experimental $\left(\varepsilon_{1}+\varepsilon_{2}\right) / 2$ as a function of pressure). The difference between $c_{3}(p)$ and $c_{1}(p)$ is maximum at pressure $p<10 \mathrm{MPa}$ as sugested by Figure 1 . The lower bound for anisotropy of adsorption stresses is estimated with the average difference $\overline{\left|c_{3}-c_{1}\right|} /\left(2 \overline{c_{1}}\right)$ equal to 0.013 for specimen $364-1$ and 0.011 for specimen $364-2$. We find that assuming a constant coupling coefficient with pressure does not capture perfectly the coal matrix linear compressibility observed experimentally at high pressures $p>10 \mathrm{MPa}$ (See Figures 1-a-d). In contrast, a better curve matching is observed by considering pressure-dependent coupling coefficients $c_{1}(p) \neq c_{3}(p)$. The recalculated swelling strains are plotted with the refitted adsorption variables $n_{0}^{\max }$ and $\beta$ in Figure 3-b,d for both specimens.

\section{Discussion}

\subsection{Comparison with empirical approaches and and non-empirical theories}

Early empirical developments simplify the effect of coal swelling in reservoir geomechanics to be analogous to that of thermal dilation [Palmer and Mansoori, 1998; Shi and Durucan, 2004], such that, coal swelling is expressed empirically by fitting a Langmuir isotherm directly to swelling strains, or assuming a linear relationship between swelling and Langmuir-fitted adsorption amount (See a comprehensive review in Pan and Connell 
X - 18 ESPINOZA ET AL.: A TRANSVERSE ISOTROPIC MODEL FOR MICROPOROUS SOLIDS

[2012]). Such empirical developments are sometimes too simplistic, as here for instance, monotonic Langmuir functions would not be able to fit well the non-monotonic swelling strains shown in Figure 1.

Other non-empirical models have been recently proposed to explain and predict the adsorption-induced swelling of coal. First, Hol and Spiers [2012] proposed a thermodynamical model to explain the Brzeszcze coal swelling data we use in this article. They base their formulation on the separation of adsorption-induced swelling and bulk fluid-driven compression (similar to Eq. 15), with the additional hypothesis of a linear relationship between total adsorption amount and adsorption strain. Our model shows fair agreement with this hypothesis for samples immersed in the adsorbate at low gas pressure $p<10$ $\mathrm{MPa}$, although deviations may occur at higher pressures when the bulk fluid pressure compression of the coal matrix prevails decreasing the total amount of adsorption (Figure 1-c,f). Anisotropy modeling is not included by Hol and Spiers [2012], although it has been considered by the same authors elsewhere [Hol et al., 2012]. Second, Vermorel et al. [2013a] developed a poromechanical formulation based on properties defined at the molecular scale, such as microporosity or microporous skeleton stiffness $K_{s}$. This formulation proposes an adsorption-mechanical coupling based on the definition of an apparent microporosity which depends on excess $n_{e x}$ and total $n_{t}$ adsorbed amounts. We find the isotropic version of our formulation compatible with theirs if $\partial n /\left.\partial \epsilon\right|_{p}=\left(1-K / K_{s}\right) n_{t} /\left(n_{t}-n_{e x}\right)$ where $\epsilon$ is the volumetric deformation (see Eq. 11). Third, Pan and Connell [2011] developed a swelling model for mesoporous solids which includes orthotropy. They base their model on a crossed-tube analogous structure. In contrast, our model does not assume a particular geometry and mechanical properties ensues naturally from continuum 
ESPINOZA ET AL.: A TRANSVERSE ISOTROPIC MODEL FOR MICROPOROUS SOLIDS X - 19 
X - 20 ESPINOZA ET AL.: A TRANSVERSE ISOTROPIC MODEL FOR MICROPOROUS SOLIDS

Brzeszcze coal sample $\left(\mathrm{CO}_{2}\right.$ pressure $p=10 \mathrm{MPa}$ - from $\varepsilon_{i j}=0$ in Eq. 13). In-situ conditions lie in between these two scenarios. In general, the adsorption isotherm is a multivariate function which depends on pressure and strains. Hence, there may be adsorption/desorption at constant fluid pressure driven by strain changes such as mechanical stretching and compression (Eq. 11 - See experimental evidence in [Hol et al., 2012; Hol and Spiers, 2012]).

\subsection{Relation between volumetric strain and total adsorption for samples} immersed in the adsorbate

Our model predicts an approximately linear relationship between total adsorption amount and strain when adsorption-induced swelling prevails for adsorption experiments with coal samples immersed in the adsorbate, i.e., at low-medium fluid pressure (Figure 4-a,b, $p<10 \mathrm{MPa}$ ). However, as predicted by our model (no adsorption amount experimental data in this pressure range), total adsorption amount may decrease as bulk fluid pressure takes more relevance and compresses the coal matrix. Improved certainty in the determination of total adsorption amount $n$ would help corroborate this last statement. Recall the fact that we follow a Lagrangian mechanical description, therefore, adsorption per unit volume of undeformed coal matrix $[\mathrm{mol} / \mathrm{L}]$ may be converted to adsorption per unit mass $[\mathrm{mol} / \mathrm{kg}]$ through the initial mass density $[\mathrm{kg} / \mathrm{L}]$. Recently published experimental data of simultaneous measurement of adsorption and swelling up to $15 \mathrm{MPa}$ show a similar shape of the swelling-adsorption signature as the one predicted by our model before the onset of coal matrix contraction (see Fig. 8 from Day et al. [2008]). Other phenomena that may affect the shape of the adsorption-strain curve include creep at con- 
ESPINOZA ET AL.: A TRANSVERSE ISOTROPIC MODEL FOR MICROPOROUS SOLIDS $\quad \mathrm{X}-21$

stant Terzaghi's effective stress and coal matrix adsorption-induced softening [Czaplinski and Holda, 1982; Hagin and Zoback, 2010; Masoudian et al., 2013].

\subsection{Adsorption-strain coupling expressed with Biot-like coefficients}

The Biot coefficient $\alpha$ was first defined as the ratio of change in fluid content $\zeta$ to dilation $\epsilon$ in a jacketed (drained) test, such that for a conventional poroelastic material $\zeta=\alpha \epsilon\left[\right.$ Biot and Willis, 1957]. Biot noted that $\alpha$ can also be identified to $1-K / K_{s k}$ (where $K$ and $K_{s k}$ are the bulk moduli measured in drained and unjacketed conditions) which provides a further interpretation of $\alpha$ different from the first definition. The fact that they yield equal values results from the symmetry of the coefficients in the poroelastic matrix and in turn from the existence of a thermodynamic potential with pressure $p$ and change in fluid content $\zeta$ as conjugate variables. In conventional poroelasticity the density of the fluid into the porosity of the material corresponds to its bulk density, therefore, the Biot coefficient $\alpha$ is less than 1 as the volume of fluid $\zeta$ entering the specimen during a drained test cannot be greater than its dilation $\epsilon$.

However, this is not the case in adsorptive materials such as coal where the density of the adsorbed fluid can be much greater than the density of the bulk fluid. In the framework of the theory developed here for transverse isotropic microporous solids, the incremental amount of fluid content $d \zeta=d\left(n \bar{V}_{b}\right)$ during a jacketed test is (from Eq. 9)

$$
d\left[n\left(p, \varepsilon_{i j}\right) \bar{V}_{b}(p)\right]=b_{1}(p) d \varepsilon_{1}+b_{1}(p) d \varepsilon_{2}+b_{3}(p) d \varepsilon_{3}
$$

where $b_{i}(p)=c_{i}(p) n_{0}(p) \bar{V}_{b}(p)$ can be coined as a (tangent) Biot-like coefficient, consistently with the first definition given by Biot. The fluid content $n \bar{V}_{b}$ is the volume (per 
X - 22 ESPINOZA ET AL.: A TRANSVERSE ISOTROPIC MODEL FOR MICROPOROUS SOLIDS

unit volume of coal) that the amount of adsorbed fluid would occupy in it were in bulk conditions. Therefore the volume change $d\left(n \bar{V}_{b}\right)$ can be much larger than the volumetric dilation increment $d \epsilon$ leading to coefficients $b_{i}(p)$ exceeding 1 . This does not contradict thermodynamics. Due to the symmetry already discussed, this coefficient $b_{i}(p)$ can still be identified to $1-K / K_{u n j}$ which is equal to $d s_{i}^{a} / d p$ here (Eq. 12), but the unjacketed bulk modulus $K_{u n j}(p)$ does not reveal the solid stiffness alone. It is a macroscopic property which also accounts for the adsorptive properties of the fluid molecules onto the solid pore walls. Vermorel et al. [2013b] defines an analogous Biot-like pressure-dependent coefficient as $b(p)=b^{\infty} n_{T}(p) /\left[n_{T}(p)-n_{\text {excess }}(p)\right]$ where $b^{\infty}<1$ is the asymptotic Biot coefficient obtained at high fluid pressure.

Given the coal adsorption properties $\left(n_{0}^{\max }, \beta, c_{i}\right)$ and the $\mathrm{CO}_{2}$ bulk molar volume $\bar{V}_{b}$, the Biot-like coefficient ranges from $b^{t} \sim 40$ to 1 for low $\mathrm{CO}_{2}$ pressure $p=0$ to $\sim 10 \mathrm{MPa}$ (adsorption prevails) and decreases asymptotically to $\sim 0.74$ as $\mathrm{CO}_{2}$ pressure increases (plotted in Figure 4-c,d as solid line for pressure-independent $c$ and as symbols for pressuredependent $\left.c_{i}(p)\right)$. The $b(p)$ curve exhibits an inflexion point which roughly coincides with the limit between adsorption-dominated swelling $b>1$ and bulk fluid-driven compression $b<1$ (Figure 4-c,d).

Although they remain nontrivial, variations of the introduced Biot-like coefficients $b_{i}$ with the fluid pressure are simpler than variations of the coupling coefficients $c_{i}$, in the sense that at least the former are monotonic. The complexity of the variations of the coefficients $c_{i}(p)$ stems from the fact that those coefficients involve characteristics of the solid, of the fluid, and of their interaction. In contrast, since $b_{i}(p)=c_{i}(p) n_{0}(p) \bar{V}_{b}(p)$, the Biot-like coefficients are corrected for variations of density of the bulk fluid. Therefore, 
ESPINOZA ET AL.: A TRANSVERSE ISOTROPIC MODEL FOR MICROPOROUS SOLIDS X - 23

when looking for a physical interpretation of the inverted parameters of the model, one might find more useful focusing on the Biot-like coefficients rather than on the more convoluted coupling coefficients $c_{i}$. For instance, in the isotropic case, Vermorel et al. [2013b] propose the physical rule of thumb that the Biot-like coefficient $b(p)$ is proportional to the ratio of the density $\rho_{\text {sorbed }}$ of the adsorbed phase to the density $\rho_{\text {free }}$ of the bulk phase (i.e., $b(p) \propto \rho_{\text {sorbed }}(p) / \rho_{\text {free }}(p)$.

\subsection{Implications for coal bed methane recovery}

The determination of strains and effective stress on the direction of the bedding plane in coal seams subjected to primary or secondary methane recovery is critical to predict changes in fracture permeability. Various permeability-stress relationships have been proposed to predict permeability, generally in the form: $\log \left(k / k_{0}\right)=a\left(\sigma_{h}+p-\sigma_{h 0}-p_{0}\right)$ (being $k_{0}$ the reference permeability at total horizontal stress $\sigma_{h 0}$ and fluid pressure $p_{0}$ and $a \sim 0.1$ to $0.2 \mathrm{MPa}^{-1}[$ Somerton et al., 1975; Pan and Connell, 2012]). Thus, a general model that predicts stresses in the anisotropic coal seam as a function of fluid pressure and boundary conditions is required for realistic predictions and simulations of coal bed methane recovery. The coal seam can be modeled as a double-porosity reservoir rock, where cleats account for macroporosity and coal matrix micropores account for the microporosity. In order to become practical at the scale of the seam, the constitutive laws derived here at the scale of the coal matrix must be upscaled to the scale of the coal seam by incorporating the presence of the cleats, in the spirit of what was done by Nikoosokhan et al. [2012]. In this upscaling, the presence of the cleats only induces regular poromechanical effects, in the sense that cleats are macropores in which adsorption-effects are negligible, and the coal matrix is responsible for adsorption-induced phenomena. This 
X - 24 ESPINOZA ET AL.: A TRANSVERSE ISOTROPIC MODEL FOR MICROPOROUS SOLIDS 
in coal samples immersed in the adsorbate represent just one path on the multivariate adsorption isotherm.

The developed fully coupled model permits inverting transverse isotropic mechanicaladsorptive properties of microporous coal matrix. Upscaling to a coal seam model which includes both macroporous cleats and microporous adsorptive coal matrix would yield the coupled constitutive equations of the coal seam. This set of fully coupled equations enable the prediction of strains and effective stress in different directions respect to the bedding plane under in-situ anisotropic state of stresses. The calculated effective stresses can be used through permeability-stress relationships for determining seam permeability.

Acknowledgments. This work was supported by Total S.A. We are thankful to R.

Vermorel, the associate editor, and anonymous reviewers for insightful comments.

\section{References}

Biot, M. A. and D. G. Willis (1957), The elastic coefficients of the theory of consolidation, Journal of Applied Mechanics, 24, 594-601.

Brochard, L., M. Vandamme, and R.-M. Pellenq (2012), Poromechanics of microporous media, Journal of the Mechanics and Physics of Solids, 60(4), 606-622, doi: 10.1016/j.jmps.2012.01.001.

Busch, A., S. Alles, Y. Gensterblum, D. Prinz, D. Dewhurst, M. Raven, H. Stanjek, and B. Krooss (2008), Carbon dioxide storage potential of shales, International Journal of Greenhouse Gas Control, 2(3), 297-308, doi:10.1016/j.ijggc.2008.03.003.

Ceglarska-Stefanska, G., and A. Czaplinski (1993), Correlation between sorption and dilatometric processes in hard coals, Fuel, 72, 413-417. 
X - 26 ESPINOZA ET AL.: A TRANSVERSE ISOTROPIC MODEL FOR MICROPOROUS SOLIDS

Ceglarska-Stefanska, G., and K. Zarebska (2002), The competitive sorption of CO2 and CH4 with regard to the release of methane from coal, Fuel Processing Technology, 77-78, $423-429$.

Cheng, A. H. -D. (1997), Material coefficients of anisotropic poroelasticity, International Journal of Rock Mechanics and Mining Sciences, 34(2), 199-205.

Cody, G. D., J. W. Larsen, and M. Siskin (1988), Anisotropic solvent swelling of coals, Energy \& Fuels, 2(3), 340-344, doi:10.1021/ef00009a020.

Coudert, F.-X., A. Boutin, M. Jeffroy, C. Mellot-Draznieks, and A. H. Fuchs (2011), Thermodynamic methods and models to study flexible metal-organic frameworks., Chemphyschem : a European journal of chemical physics and physical chemistry, 12(2), 247-58, doi:10.1002/cphc.201000590.

Coussy, O. (2004), Poromechanics, 298p., Wiley.

Coussy, O. (2010), Mechanics and Physics of Porous Solids, 281p., Wiley.

Cowin, S. C. (2004), Anisotropic poroelasticity: fabric tensor formulation, Mechanics of Materials, 36, 665-677.

Cui, X., R. M. Bustin, and L. Chikatamarla (2007), Adsorption-induced coal swelling and stress: Implications for methane production and acid gas sequestration into coal seams, Journal of Geophysical Research, 112(B10202), doi:10.1029/2004JB003482.

Czaplinski, A., and S. Holda (1982), Changes in mechanical properties of coal due to sorption of carbon dioxide vapour, Fuel, 61, 1281-1282.

Day, S., R. Fry, and R. Sakurovs (2008), Swelling of Australian coals in supercritical CO2, International Journal of Coal Geology, 74(1), 41-52, doi:10.1016/j.coal.2007.09.006. 
ESPINOZA ET AL.: A TRANSVERSE ISOTROPIC MODEL FOR MICROPOROUS SOLIDS X - 27

Day, S., R. Fry, R. Sakurovs, and S. Weir (2010), Swelling of Coals by Supercritical Gases and Its Relationship to Sorption, Energy $\&$ Fuels, 24(4), 2777-2783, doi: 10.1021/ef901588h.

Ding, H., W. Chen, and L. Zhang (2006), Elasticity of transversely isotropic materials, 444 pp., Springer.

Fowler, R. H. (1935), A statistical derivation of Langmuirs adsorption isotherm, Mathematical Proceedings of the Cambridge Philosophical Society, 31(2), 260-264.

Gensterblum, Y., P. V. Hemert, P. Billemont, E. Battistutta, A. Busch, B. Krooss, G. D. Weireld, and K. Wolf (2010), European inter-laboratory comparison of high pressure CO2 sorption isotherms II: Natural coals, International Journal of Coal Geology, 84(2), 115-124, doi:10.1016/j.coal.2010.08.013.

Hagin, P., and M. D. Zoback (2010), Laboratory studies of the compressibility and permeability of low-rank coal samples from the Powder River Basin, Wyoming, USA, in ARMA 10-170.

Hol, S., C. J. Peach, and C. J. Spiers (2011), A new experimental method to determine the CO2 sorption capacity of coal, Energy Procedia, 4, 3125-3130.

Hol, S., C. J. Peach, and C. J. Spiers (2011), Applied stress reduces the CO2 sorption capacity of coal, International Journal of Coal Geology, 85(1), 128-142, doi: 10.1016/j.coal.2010.10.010.

Hol, S., and C. J. Spiers (2012), Competition between adsorption-induced swelling and elastic compression of coal at CO2 pressures up to 100MPa, Journal of the Mechanics and Physics of Solids, 60(11), 1862-1882, doi:10.1016/j.jmps.2012.06.012. 
X - 28 ESPINOZA ET AL.: A TRANSVERSE ISOTROPIC MODEL FOR MICROPOROUS SOLIDS

Hol, S., C. J. Peach, and C. J. Spiers (2012), Effect of 3-D stress state on adsorption of CO2 by coal, International Journal of Coal Geology, 93, 1-15, doi:10.1016/j.coal.2012.01.001.

Johnston, J. E., and N. I. Christensen (1995), Seismic anisotropy of shales, Journal of Geophysical Research, 100(B4), 5991-6003.

Kowalczyk, P., A. Ciach, and A. V. Neimark (2008), Adsorption-induced deformation of microporous carbons: pore size distribution effect., Langmuir : the ACS journal of surfaces and colloids, 24(13), 6603-8, doi:10.1021/la800406c.

Levine, J. R. (1996), Model study of the influence of matrix shrinkage on absolute permeability of coal bed reservoirs, Geological Society, London, Special Publications, 109, 197-212, doi:10.1144/gsl.sp.1996.109.01.14.

Masoudian, M., D. Airey, and A. El-Zein (2013), A chemo-poro-mechanical model for sequestration of carbon dioxide in coalbeds, Geotechnique, 63(3), 235-243.

Mazumder, S. (2007), Dynamics of CO2 in coal as a reservoir, Ph.D. thesis, Delft University.

Mazumder, S., A. Karnik, and K. H. Wolf (2006), Swelling of coal in response to CO2 sequestration for ECBM and its effect on fracture permeability, SPE Journal,11(3), pp. $390-398$.

Moffat, D. H., and K. E. Weale (1954), Sorption by coal of methane at high pressure, Fuel, 34, 449-462.

Morcote, A., G. Mavko, and M. Prasad (2010), Dynamic elastic properties of coal, Geophysics, 75 (6), E227, doi:10.1190/1.3508874.

Neimark, A. V., F.-X. Coudert, C. Triguero, A. Boutin, A. H. Fuchs, I. Beurroies, and R. Denoyel (2011), Structural transitions in MIL-53 (Cr): view from outside and 
ESPINOZA ET AL.: A TRANSVERSE ISOTROPIC MODEL FOR MICROPOROUS SOLIDS X - 29

inside., Langmuir : the ACS journal of surfaces and colloids, 27(8), 4734-41, doi: 10.1021/la200094x.

Nikoosokhan, S., M. Vandamme, P. Dangla (2012), A poromechanical model for coal seams injected with carbon dioxide: from an isotherm of adsorption to a swelling of the reservoir, Oil $\& 3$ Gas Science and Technology Rev. IFP, Energies nouvelles, 67(5), $777-786$.

Ottiger S., R. Pini, G. Storti, M. Mazzotti, R. Bencini, F. Quattrocchi, G. Sardu, and G. Deriue (2006), Adsorption of pure carbon dioxide and methane on dry coal from the Sulcis coal province (SW Sardinia, Italy), Environmental Progress, 25(4), 355-364, doi:10.1002/ep.10169.

Palmer, I., and J. Mansoori (1998), How Permeability Depends on Stress and Pore Pressure in Coalbeds: A New Model, Evaluation, (December), 539-544.

Pan, Z., and L. D. Connell (2011), Modelling of anisotropic coal swelling and its impact on permeability behaviour for primary and enhanced coalbed methane recovery, International Journal of Coal Geology, 85(3-4), 257-267, doi:10.1016/j.coal.2010.12.003.

Pan, Z., L. D. Connell, and M. Camilleri (2010), Laboratory characterisation of coal reservoir permeability for primary and enhanced coalbed methane recovery, International Journal of Coal Geology, 82, 252-261.

Pan, Z. J., and L. D. Connell (2007), A theoretical model for gas adsorption-induced coal swelling, International Journal of Coal Geology, 69, 243-252.

Pan, Z. J., and L. D. Connell (2012), Modelling permeability for coal reservoirs: A review of analytical models and testing data, International Journal of Coal Geology, 92, 1-44. 
X - 30 ESPINOZA ET AL.: A TRANSVERSE ISOTROPIC MODEL FOR MICROPOROUS SOLIDS

Pekot, J. L., and S. R. Reeves (2002), Modeling coal matrix shrinkage and differential swelling with CO2 injection for enhanced coalbed methane recovery and carbon sequestration applications, Tech. rep., Advanced Resources International, Houston, Texas.

Pijaudier-Cabot, G., R. Vermorel, C. Miqueu, and B. Mendiboure (2011), Revisiting poromechanics in the context of microporous materials, Comptes Rendus Mécanique, 339 (12), 770-778, doi:10.1016/j.crme.2011.09.003.

Pini, R., S. Ottiger, G. Storti, and M. Mazzotti (2009), Pure and competitive adsorption of CO2, CH4 and N2 on coal for ECBM, Energy Procedia, 1(1), 1705-1710, doi: 10.1016/j.egypro.2009.01.223.

Pone, J. D. N., P. M. Halleck, and J. P. Mathews (2009), Sorption Capacity and Sorption Kinetic Measurements of CO2 and CH4 in Confined and Unconfined Bituminous Coal, Energy \&6 Fuels, 23(9), 4688-4695, doi:10.1021/ef9003158.

Ravikovitch, P. I., and A. V. Neimark (2006), Density functional theory model of adsorption deformation., Langmuir : the ACS journal of surfaces and colloids, 22(26), 10,864-8, doi:10.1021/la061092u.

Reucroft, P. J., and A. R. Sethuraman (1987), Effect of pressure on carbon dioxide induced coal swelling, Energy Fuels, 1, 72-75.

Slatt, R. M., and Y. Abousleiman (2011), Merging sequence stratigraphy and geomechanics for unconventional gas shales, The Leading Edge, 30(3), 274-282, doi: 10.1190/1.3567258.

Shi, J. Q., and S. Durucan (2004), Drawdown induced changes in permeability of coalbeds: A new interpretation of the reservoir response to primary recovery, Transport in Porous Media, 56, 1-16. 
ESPINOZA ET AL.: A TRANSVERSE ISOTROPIC MODEL FOR MICROPOROUS SOLIDS X - 31

Sloan, E. D., and C. A. Koh (2008), Clathrate hydrates of natural gases - Third edition, 701 ST - Clathrate hydrates of natural gases - Th pp., CRC Press, Boca Raton, FL.

Somerton, W. H., I. M. Soylemezoglu, and R.C. Dudley (1975), Effect of stress on permeability of coal, Int. J. Rock Mech. Min. Sci. \& Geomech. Abstr., 12, 129-145.

Span, R., and W. Wagner (1996), A new equation of state for carbon dioxide covering the fluid region from the triple-point temperature to $1100 \mathrm{~K}$ at pressures up to $800 \mathrm{MPa}$, Journal of Physical and Chemical Reference Data, 25, 1509-1596.

Thomsen, L. (1986), Weak elastic anisotropy, Geophysics, 51(10), 1954-1966.

Ulm, F.-J., M. Vandamme, C. Bobko, J.A. Ortega, K. Tai, and C. Ortiz (2007), Statistical Indentation Techniques for Hydrated Nanocomposites: Concrete, Bone, and Shale, Journal of the American Ceramic Society, $90(9), 2677-2692$, doi:10.1111/j.15512916.2007.02012.x.

van Bergen, F., S. Hol, and C. Spiers (2011), Stressstrain response of pre-compacted granular coal samples exposed to $\mathrm{CO} 2, \mathrm{CH} 4, \mathrm{He}$ and Ar, International Journal of Coal Geology, 86(2-3), 241-253, doi:10.1016/j.coal.2011.02.007.

Vandamme M., L. Brochard, B. Lecampion, and O. Coussy (2010), Adsorption and strain: The CO2-induced swelling of coal, Journal of Mechanics and Physics of Solids, 58, $1489-1505$.

Vandenbroucke, M., and C. Largeau (2007), Kerogen origin, evolution and structure, Organic Geochemistry, 38(5), 719-833, doi:10.1016/j.orggeochem.2007.01.001.

Vermorel, R., G. Pijaudier-Cabot, C. Miqueu, and B. Mendiboure (2013), 2. Poromechanics of Saturated Isotropic Nanoporous Materials, in Damage Mechanics of Cementitious Materials and Structures, eds.: G. Pijaudier-Cabot and F. Dufour. 
$\mathrm{X}-32$ ESPINOZA ET AL.: A TRANSVERSE ISOTROPIC MODEL FOR MICROPOROUS SOLIDS

602

603

604

605

606

607

608

Vermorel, R., and G. Pijaudier-Cabot (2013b), Enhanced continuum poromechanics to account for adsorption induced swelling of saturated isotropic nanoporous materials, in Poromechanics V, eds.: C. Hellmich, B. Pichler, and D. Adam.

Vernik, L., and A. Nur (1992), Ultrasonic velocity and anisotropy of hydrocarbon source rocks, Geophysics, 57(5), 727-735.

Wang, Z. (2002), Seismic anisotropy in sedimentary rocks, part 2: Laboratory data, Geophysics, 67(5), 1423-1440.

Wang S., D. Elsworth, and J. Liu (2011), Permeability evolution in fractured coal: The roles of fracture geometry and water-content, International Journal of Coal Geology, 87 (1), 13-25, doi:10.1016/j.coal.2011.04.009.

Weniger, P., W. Kalkreuth, A. Busch, and B. M. Krooss (2010), High-pressure methane and carbon dioxide sorption on coal and shale samples from the Paraná Basin, Brazil, International Journal of Coal Geology, 84(3-4), 190-205, doi:10.1016/j.coal.2010.08.003. 
a) Specimen $364-1$

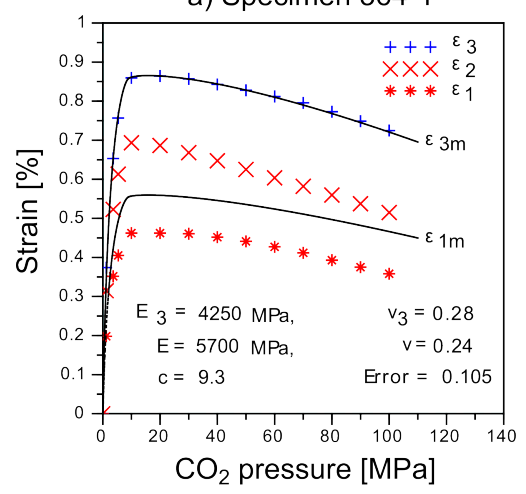

d) Specimen 364-2

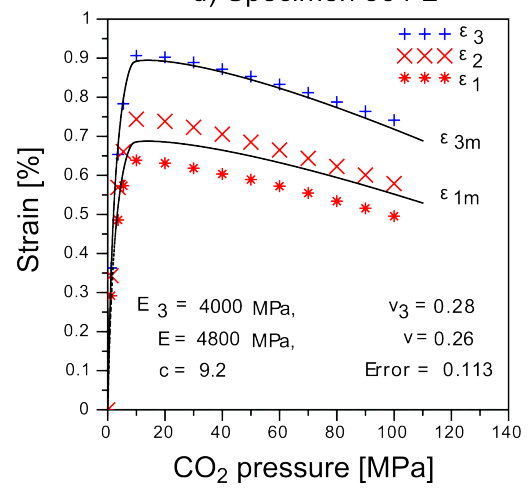

b) Anisotropy $364-1$

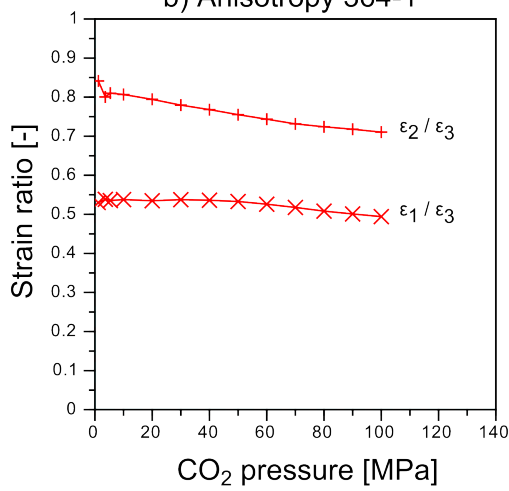

e) Anisotropy 364-2

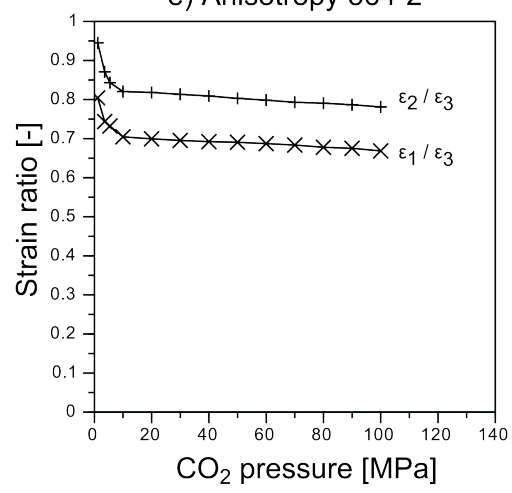

c) Total Adsorption 364-1

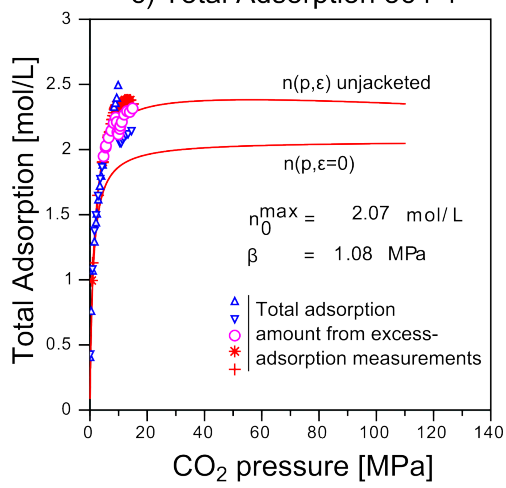

f) Total Adsorption 364-2

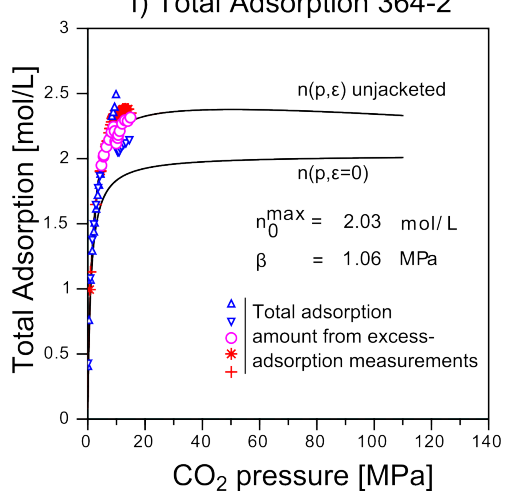

Figure 1. Adsorption-induced swelling of coal immersed in $\mathrm{CO}_{2}$. (a) Experimental measurements (symbols: principal strains $\varepsilon_{1}, \varepsilon_{2}, \varepsilon_{3}$ - original data set from Hol and Spiers [2012]) and transverse isotropic microporous model predictions considering mechanical anisotropy only $c_{1}(p)=c_{3}(p)=c$ (lines: $\varepsilon_{1 m}, \varepsilon_{3 m}$ fit $\left(\varepsilon_{1}+\varepsilon_{2}\right) / 2$ and $\varepsilon_{3}$ respectively). (b) Swelling anisotropy: strain ratios $\varepsilon_{1}$ and $\varepsilon_{2}$ respect to the major principal strain $\varepsilon_{3}$ perpendicular to the bedding plane. (c) Total adsorption amount estimated from excess sorption measurements (symbols see Auxiliary Material) and model fitted prediction (Eq. 9). (a,b,c) Specimen 364-1. (d,e,f) Specimen 364-2. 
a) Specimen $364-1$

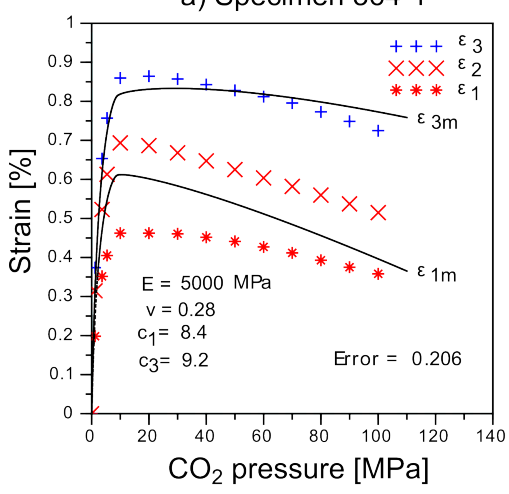

c) Specimen $364-2$

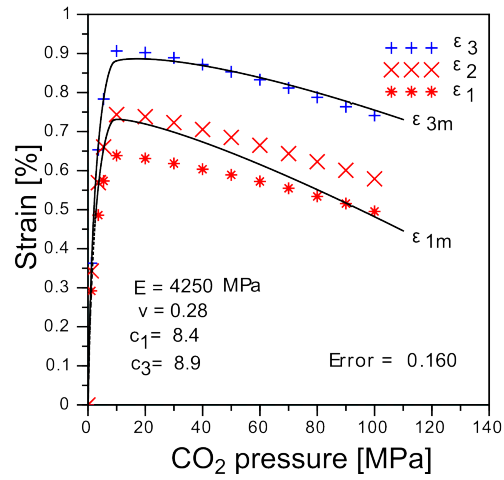

b) Total Adsorption 364-1

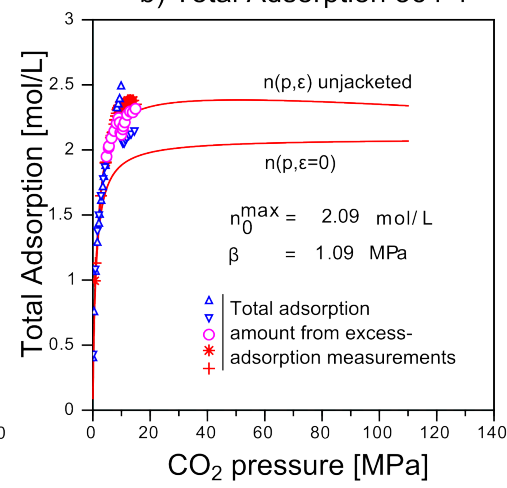

d) Total Adsorption 364-2

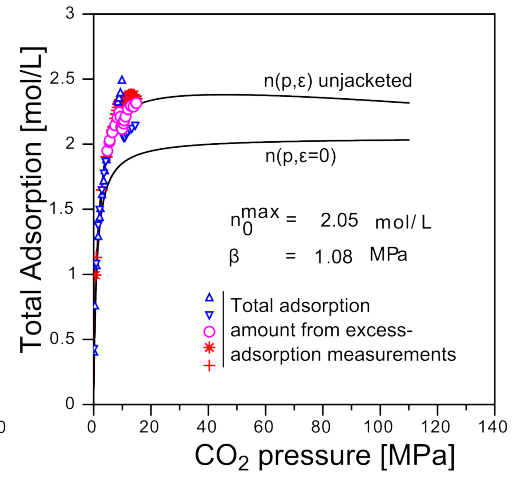

Figure 2. Adsorption-induced swelling of coal immersed in $\mathrm{CO}_{2}$. (a) Experimental measurements (symbols: principal strains $\varepsilon_{1}, \varepsilon_{2}, \varepsilon_{3}$ - original data set from Hol and Spiers [2012]) and transverse isotropic microporous model predictions considering anisotropy on adsorption stresses only $E=E_{3}$ and $\nu=\nu_{3}$ (lines: $\varepsilon_{1 m}, \varepsilon_{3 m}$ fit $\left(\varepsilon_{1}+\varepsilon_{2}\right) / 2$ and $\varepsilon_{3}$ respectively). (b) Total adsorption amount estimated from excess sorption measurements (symbols - Auxiliary Material) and model fitted prediction (Eq. 9). (a,b) Specimen 364-1. (c,d) Specimen 364-2. 
a) Coupling coefficient $364-1$

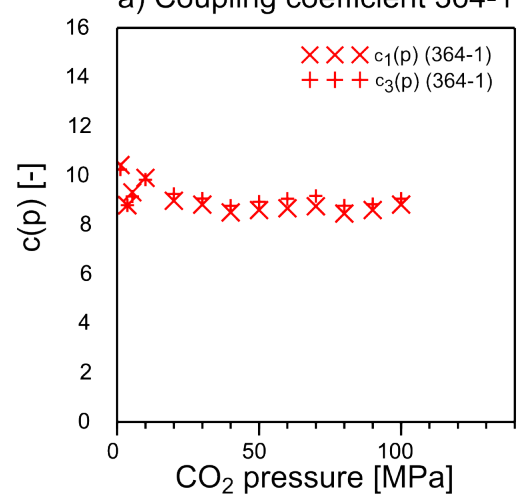

c) Coupling coefficient 364-2

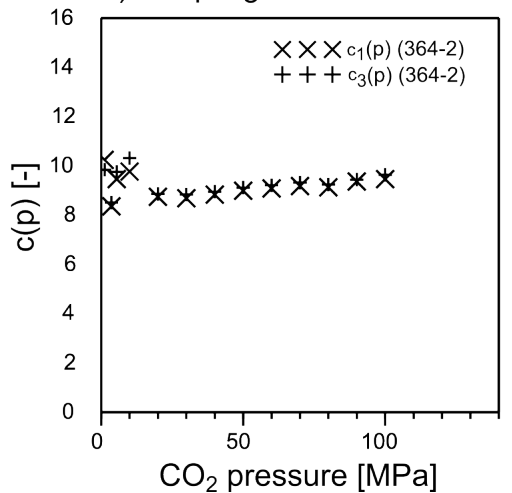

b) Strains 364-1

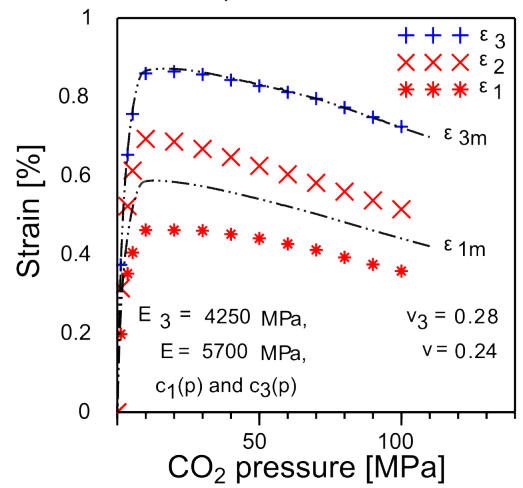

d) Strains 364-2

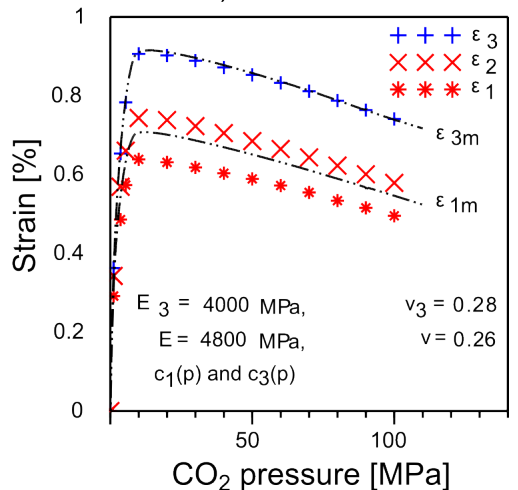

Figure 3. Determination of adsorption-strain coupling coefficients as a function of pressure for finding minimum adsorption stress anisotropy. (a) Calculated coupling coefficient $c_{i}(p)$ in the bedding plane and perpendicular to the bedding plane (Eq. 19). (b) Transverse isotropic microporous model predictions (lines: $\left.\varepsilon_{1 m}, \varepsilon_{3 m}\right)$ considering $c_{i}(p)$ previously calculated and refitted $n_{0}^{\max }$ and $\beta$ compared to experimental data - original data set from Hol and Spiers [2012]. (a,b) Specimen 364-1 - refitted $n_{0}^{\max }=2.04 \mathrm{~mol} / \mathrm{L}$ and $\beta=1.08$. (d,e) Specimen 364-2 - refitted $n_{0}^{\max }=2.00 \mathrm{~mol} / \mathrm{L}$ and $\beta=1.06$. 
a) Strain VS Adsorption 364-1

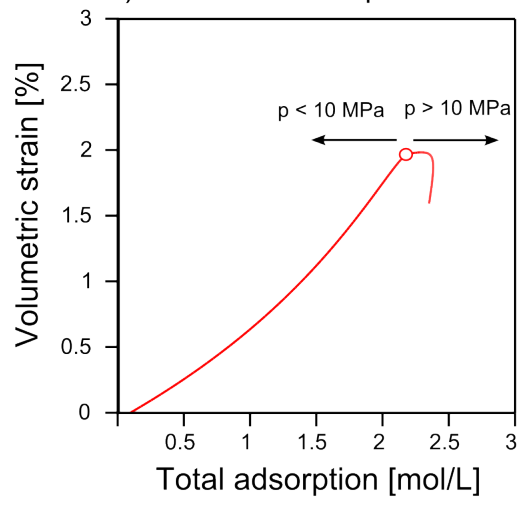

c) Strain VS Adsorption 364-2

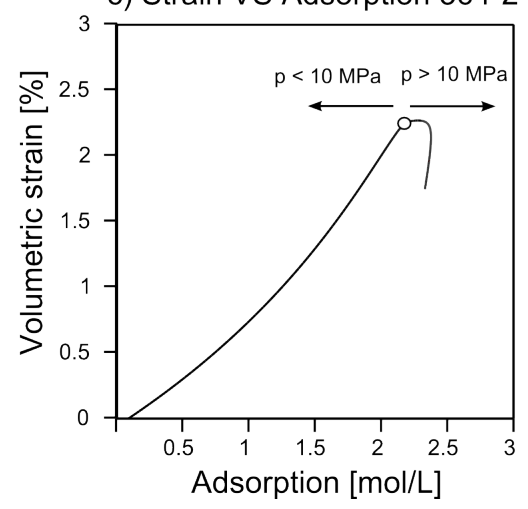

b) Biot-like coefficient 364-1

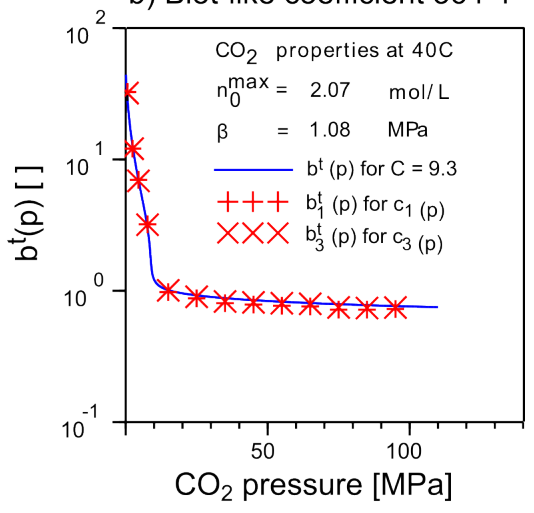

d) Biot-like coefficient 364-2

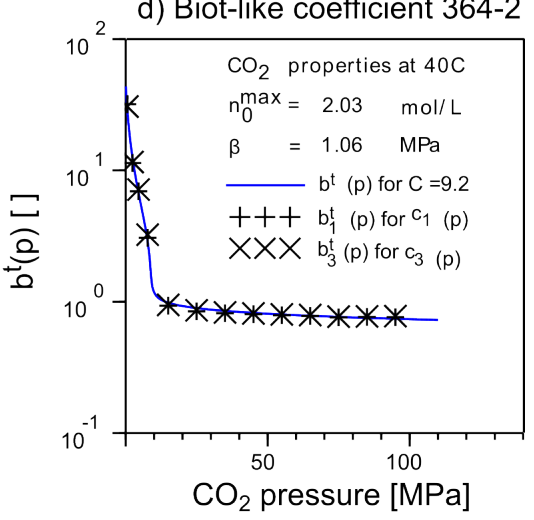

Figure 4. Insight into the poromechanics of coal matrix. (a) Model-predicted volumetric strain as a function of total adsorption amount for coal immersed in $\mathrm{CO}_{2}$ (model parameters from Figure 1). (b) Biot-like pressure dependent functions $b_{i}^{t}(p)$. (a,b) Specimen 364-1. (c,d) Specimen 364-2. 